\title{
Correction: Terunuma et al. A Cohort Study on Respiratory Symptoms and Diseases Caused by Toner-Handling Work: Longitudinal Analyses from 2003 to 2013. Atmosphere 2019, 10, 647
}

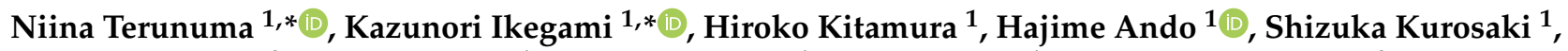 \\ Masashi Masuda ${ }^{2}$, Takeshi Kochi ${ }^{1}$, Nobuaki Yanagi ${ }^{1}$, Akira Ogami ${ }^{1}$ and Toshiaki Higashi ${ }^{3}$ \\ 1 Department of Work Systems and Health, Institute of Industrial Ecological Sciences, \\ University of Occupational and Environmental Health, Kitakyushu 807-8555, Japan; \\ h-kita@med.uoeh-u.ac.jp (H.K.); h-ando@med.uoeh-u.ac.jp (H.A.); kurosaki@med.uoeh-u.ac.jp (S.K.); \\ t-kochi@med.uoeh-u.ac.jp (T.K.); n-yanagi@med.uoeh-u.ac.jp (N.Y.); gamisan@med.uoeh-u.ac.jp (A.O.) \\ 2 Human Resources Department, AEON Co., Ltd., Chiba 261-8515, Japan; masashi@med.uoeh-u.ac.jp \\ 3 University of Occupational and Environmental Health, Kitakyushu 807-8555, Japan; \\ thigashi@med.uoeh-u.ac.jp \\ * Correspondence: terunuma@med.uoeh-u.ac.jp (N.T.); kikegami@med.uoeh-u.ac.jp (K.I.); \\ Tel.: +81-93-603-1611 (N.T. \& K.I.)
}

check for updates

Citation: Terunuma, N.; Ikegami, K.; Kitamura, H.; Ando, H.; Kurosaki, S.; Masuda, M.; Kochi, T.; Yanagi, N.; Ogami, A.; Higashi, T. Correction: Terunuma et al. A Cohort Study on Respiratory Symptoms and Diseases Caused by Toner-Handling Work: Longitudinal Analyses from 2003 to 2013. Atmosphere 2019, 10, 647. Atmosphere 2021, 12, 910. https:// doi.org/10.3390/atmos12070910

Received: 1 July 2021

Accepted: 8 July 2021

Published: 15 July 2021

Publisher's Note: MDPI stays neutral with regard to jurisdictional claims in published maps and institutional affiliations.

Copyright: (c) 2021 by the authors. Licensee MDPI, Basel, Switzerland. This article is an open access article distributed under the terms and conditions of the Creative Commons Attribution (CC BY) license (https:// creativecommons.org/licenses/by/ $4.0 /)$.
There were errors in the original article [1]. It was incorrect to state that the incidence rates of lung cancer per 100,000 person-years in the toner-handling and non-toner-handling groups and the $95 \%$ confidence interval for the incidence rate of lung cancer per 100,000 person-years in the non-toner-handling group were 37.2, 39.0, and 3.7-114.6, respectively. In addition, incidence rate ratio for lung cancer was mistakenly described as "The odds ratio for lung cancer". Since the statements regarding the incidence of respiratory diseases, including lung cancer, in the two groups were also in the abstract and discussion sections, so these sections needed to be corrected together.

A correction has been made to Abstract:

The purpose of this study was to examine the effects of toner-handling work on respiratory symptoms and diseases. We conducted a prospective cohort study of 1468 workers between 2003 and 2013. The cohort included 887 toner-handling workers and 581 nontoner-handling workers, employed in one toner and copier manufacturing enterprise. Toner-handling workers were subdivided into two groups based on the 8-h time-weighted average toner exposure concentration for each work category in the baseline survey. We compared the incidence of respiratory disease and longitudinal changes in the prevalence of subjective respiratory symptoms among three groups, as follows: High-concentration toner exposure group, the low-concentration toner exposure group, and a control group. The incidence of respiratory disease and changes in the prevalence of subjective respiratory symptoms were not significantly different between the non-toner-handling group and the toner-handling group. In contrast, the odds ratio for yearly changes in the prevalence of wheezing without asthmatic response was significantly lower in the high-concentration toner exposure group than in the control group. At the study site, dust scattering was well controlled and workers used respiratory protection appropriately. These findings suggest that toner-handling work had little adverse effect on respiratory function in a work environment with sufficiently controlled ventilation.

A correction has been made to Results, Incidence of Respiratory Diseases, Paragraph 2:

The incidence rate of lung cancer per 100,000 person-years was 38.4 (95\% confidence interval (CI):13.0-112.8) in the toner-handling group and 19.5 (95\% CI: 3.4-110.4) in the non-toner-handling group. The ratio for the incidence rate of lung cancer in the toner 
handling group relative to the non-toner-handling group was 1.97 (95\% CI: 0.20-18.9), indicating no significant difference.

A correction has been made to Discussion, Paragraph 1:

This 10-year cohort study of employees of a toner and copy machine manufacturing enterprise in Japan used questionnaire data to explore the chronic effects of toner-handling work on the incidence of respiratory diseases and yearly changes in subjective respiratory symptoms. We found that there was no significant difference in the incidence of respiratory diseases between the toner-handling group and the non-toner-handling group. Similarly, toner-handling work had no definitive effect on the prevalence of chronic cough, chronic phlegm, chronic cough and phlegm, or shortness of breath. However, toner-handling work had significant effects only on yearly changes in wheezing without asthmatic response in the high-concentration toner exposure group.

There was an error in the original article [1]. The number of samples in the high-con centration toner exposure group was incorrectly stated as 47 in one place.

A correction has been made to Discussion, Paragraph 13:

This study had a number of limitations. First, the number of samples in the highconcentration toner exposure group was 49 , which may have been insufficient to detect the difference among three independent group proportions. In accordance with a common industrial health survey guide, Japanese toner manufacturers are currently cooperating to implement cohort surveys to determine the health effects of toner dust at individual companies [45]. In the future, pooled analyses based on such survey results from multiple companies will be useful for analyzing the dose-response relationship between toner dust exposure and symptoms. Second, a 10-year survey period may have been insufficient. Onsets of the endpoint respiratory disease, for the most part, require long exposure times. It may be necessary to continue to follow-up the participants in the toner-handling group. Third, because follow-up was discontinued with the occurrence of the endpoint disease, we may have missed other endpoint diseases that occurred after the follow-up. Accordingly, it is possible that the health risk of toner-handling work was estimated to be low. Fourth, because toner-handling work tends to be associated with larger physical workloads than non-toner-handling work, employees with critical health issues may have been engaged in toner-handling work. This healthy worker bias [30] may have led to an underestimation of the risk associated with toner-handling work. Finally, the toner exposure concentrations at the study sites may have been low. This may be because the work environment was appropriately managed to prevent dust scattering (using exhaust equipment). Moreover, workers who frequently worked with toner were instructed to observe the rules for respiratory mask expiration and periodic exchanging of filters. In addition, from the perspective of safety and hygiene, toner dust concentrations were measured outside the respiratory masks. The actual levels inhaled were therefore likely lower than the measured toner dust concentrations.

The authors apologize for any inconvenience caused and state that the scientific conclusions are unaffected. The original article has been updated.

Author Contributions: Methodology, T.H.; Validation, N.T., K.I., H.K. and A.O.; Formal analysis, N.T.; Investigation, N.T., K.I., H.K., H.A., S.K., M.M., T.K. and N.Y.; Data curation, N.T., K.I. and H.K.; Writing—original draft, N.T.; Writing—review \& editing, K.I.; Supervision, A.O. and T.H.; Project administration, A.O. and T.H.; Funding acquisition, A.O. and T.H. All authors have read and agreed to the published version of the manuscript.

Funding: This study was funded by Fuji Xerox Co., Ltd. (project No. toner cohort_20030332 entitled "The relationship between toner-handling work and health effects," project managers: Akira Ogami and Toshiaki Higashi).

Institutional Review Board Statement: The study was conducted according to the guidelines of the Declaration of Helsinki, and approved by the Ethics Committee of Medical Research, University of Occupational and Environmental Health, Japan (no. 03-32, 10 December 2003). 
Informed Consent Statement: Informed consent was obtained from all subjects involved in the study. Conflicts of Interest: The authors declare no conflict of interest.

\section{Reference}

1. Terunuma, N.; Ikegami, K.; Kitamura, H.; Ando, H.; Kurosaki, S.; Masuda, M.; Kochi, T.; Yanagi, N.; Ogami, A.; Higashi, T. A Cohort Study on Respiratory Symptoms and Diseases Caused by Toner-Handling Work: Longitudinal Analyses from 2003 to 2013. Atmosphere 2019, 10, 647. [CrossRef] 